\title{
The refugee camp management: a general framework and a unifying decision-making model
}

\author{
Ozlem Karsu and Bahar Y. Kara \\ Bilkent Universitesi, Ankara, Turkey, and \\ Bayram Selvi \\ Turk Kizilayi, Ankara, Turkey
}

The refugee

camp

management

Received 19 January 2018

Revised 27 July 2018

18 December 2018

Accepted 21 December 2018

\begin{abstract}
Purpose - Motivated by the increasing need to provide support to refugees, which remains as a pressing issue in the agenda of many countries, the purpose of this paper is to consider the refugee camp management problem. Although each of these countries may have different procedures shaped by their own culture, rules and regulations, the main structure of the problem can be modeled utilizing a general framework which will apply to different practices.

Design/methodology/approach - In this study, the authors consider the issue with an operations research (OR) perspective and provide such a framework utilizing Turkish Red Crescent (TRC)'s field expertise in many regions of the world. In the proposed framework, the overall refugee camp management problem is first categorized in two main phases: the establishment phase, which consists of one-time decisions like infrastructure design and the administration phase, which focuses on routine decisions that are taken on a periodic basis like aid distribution.

Findings - The authors then provide a unifying decision-making model for the establishment phase and detail the administrative phase via subcategories, linking the relevant problems to the OR literature. The proposed framework is general enough to be used by practitioners and to be utilized by the academicians to define new OR problems to the literature.

Originality/value - TRC's know-how is very broad and extensive. Integrating that know-how with OR perspective, the authors provide a general framework that could be of use to practitioners as well as academicians. The proposed framework will constitute an example for countries of asylum and national or international NGOs to manage the refugee camps efficiently. The authors also highlight main challenges and dynamics of the decision-making problems encountered in different parts of the proposed framework, which may constitute many different problems to the OR literature each of which can open new venues for future research.
\end{abstract}

Keywords Humanitarian operations, Camp administration, Camp establishment,

Refugee camp management

Paper type General review

\section{Introduction}

The Syrian Crisis led to one of the most challenging problems of the world today. Since the beginning of 2011, millions of Syrian people fled the civil war and migrated to other countries, mostly the neighbors. Sharing a border with Syria, Turkey hosts millions of Syrian people today. As of March 2018, there are 25 refugee camps established mainly in the southern part of Turkey. In addition to these camps, there are Syrian people living within the cities. Currently, 6 percent of the over $3.5 \mathrm{~m}$ Syrian refugees are living within the camps and the rest are trying to live with the locals in the community. Even this 6 percent is actually a huge number and the camps are fully utilized. Motivated by the sudden need for refugee management, different countries utilized different approaches. Jahre et al. (2018) analyze four different refugee camps, each having their own dynamics, in Ethiopia, Kenya, Greece and Turkey. The first two are actually not related with the Syrian crisis, pointing out

The authors would like to thank the anonymous referees who have contributed in the further development of this manuscript by their suggestions and comments.

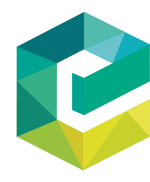

Journal of Humanitarian Logistics and Supply Chain Management Vol. 9 No. 2, 2019 pp. $131-150$

(C) Emerald Publishing Limited DOI 10.1108/JHLSCM-01-2018-0007 
JHLSCM

9,2

the fact that refugee camps are actually not new to the world. However, due to the 2011 crisis, the need increased substantially.

The refugee camp management problem is very challenging due to the difficulties as geographical discrepancies and unknown time span of the need for the refugee camps. However, few studies have been conducted on the scope of refugee management in the operations research (OR) literature so far. There are many reports forming an established gray literature (Jahre et al., 2018). How to link this literature to OR remains an open venue for further research.

In this study, we aim to discuss main processes related to management of a refugee camp with an OR point of view. We worked in close collaboration with one of the main responsible institutions: Turkish Red Crescent (TRC). Integrating TRC's know-how with OR perspective, we manage to visualize these processes and their interaction. We study all the aspects of the refugee camp management problem from the most strategic level concerning the location decision to daily decisions in the administrative level. Observing the decision-making problems that TRC is facing through the process, we structure these problems in a way that the OR practitioners and researchers will be able to relate to and offer solution methodologies. The main contribution of this paper is establishing this link within a general framework.

We categorized our analysis into two: the establishment phase, where we focus on the main decisions regarding the establishment of the refugee camps and the administration phase, where we study the tactical and operational issues for everyday life at refugee camps. We first consider the establishment phase in detail. For the infrastructure-related decisions, we provide a unifying mathematical model, with a bi-level structure. This part would provide new insights for researchers since the proposed bi-level structure has not been discussed in the OR literature yet.

The output of the analysis in the establishment phase will provide the final camp layout, which is the main input of the administrative phase. The discussion we provide on the administration phase is mainly for practitioners as we aim to define the sub-problems of each phase in detailed manner and link these problems with OR literature. We provide references to studies offering OR solutions for each problem type that we detect in the administrative phase, so as to guide practitioners to relevant works that they can benefit from. For the practitioners who are well aware of the problems but looking for structured methods to solve them, this work can be an introduction to the well-established OR tools. Hence, in Section 5 we give general guidelines mainly for practitioners by pointing out relevant literature. We, however, do not present an exhaustive literature review, rather provide examples from the literature. From the OR point of view, the dynamics of refugee camp management will introduce new challenges to the underlying OR problems, which will open new venues to enhance the theory and practice of OR. Specifically, the discussion on the sub-problems in the administrative phase might lead to works that will enhance the OR theory, mainly in terms of applications.

The paper is organized as follows: in Section 2, we summarize the current situation in the world followed by a more detailed overview of the Syrian refugees in Turkey. The section also details the help provided by the TRC, which is one of the main solution partners. In Section 3, we provide the framework that we proposed for refugee camp management accompanied with a visualized overview of all sub-systems. Section 4 details the establishment phase. We first provide a combinatorial formulation in Subsection 4.1 for the general block design structure together with the interrelations of the required facilities. Subsection 4.2 discusses the specifics of water and energy network designs for a selected camp location and capacity. In Section 5, we analyze the refugee camp administration problem with specific attention to safety and security, health and sanitation, education and psycho-social activities, aid management and transportation services. 
While detailing the refugee camp administration problems, we highlight various OR problems that are relevant to link the practice with the literature. The paper ends with concluding remarks in Section 6.

\section{Refugee situation}

A refugee is "someone who has been forced to flee his or her country because of persecution, war, or violence" according to the definition of UNHCR (2016a). Additionally, an internally displaced person (IDP) is "a person who has been forced to flee his or her home for the same reason as a refugee, but remains in his or her own country and has not crossed an international border." In terms of structural features, the refugee and IDP issues can be analyzed under the same headline (Kennedy, 2004).

Today, the world is facing one of the biggest refugee movements. The Syrian civil war began in 2011 when thousands of Syrian citizens fled across the border to neighboring Turkey, Lebanon, Jordan and Iraq. The list of the number of Syrian refugees in neighboring countries, as of 2017, is given in Table I (UNHCR, 2017).

Some of the refugees have even migrated beyond countries in Europe, North Africa and the Caucasus. Figure 1 demonstrates the number of asylum seekers in European countries for 2016 and 2017.

However, these numbers may not be certain, as some refugees may have passed through borders or arrived by sea undetected. As the figure demonstrates, Germany has received the highest number of asylum seekers within Europe. These figures show that the majority of Syrian refugees resides in Turkey. According to official information from UNHCR (2016b), Turkey hosts roughly 60 percent of Syrian refugees in the world.

\begin{tabular}{lc}
\hline Country & Number of Syrian refugees \\
\hline Turkey & $3,541,572$ \\
Lebanon & $1,001,051$ \\
Jordan & 664,877 \\
Iraq & 246,592 \\
Egypt & 126,027
\end{tabular}

Source: UNHCR (2017)
The refugee camp

management
Table I. The number of refugees in neighboring countries (as of November 2017)

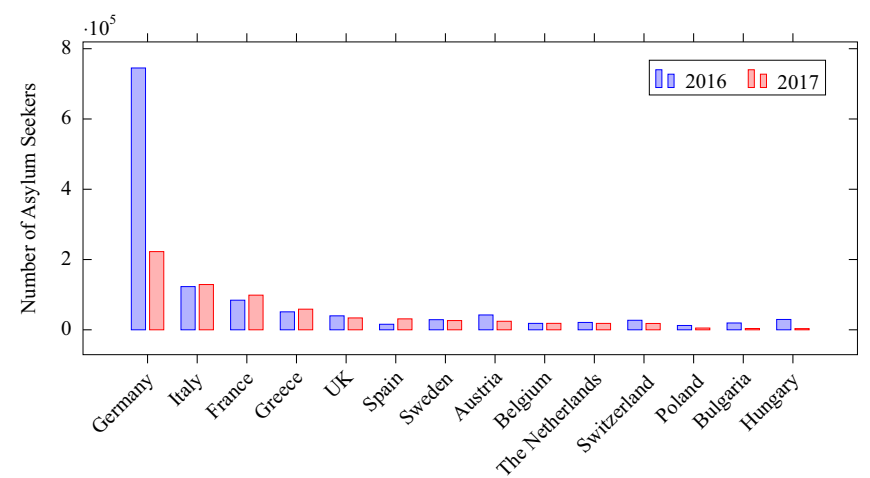

Figure 1.

Total number of asylum seekers in the EU

Source: Eurostat (2018) 
JHLSCM

9,2

Besides Syrian refugees, Turkey also witnessed an unprecedented increase in asylum applications from Afghans, Iraqis and Iranians since 2014 (UNHCR, 2016c). According to the UNHCR, by July 2016, Iraqi and Afghan refugees and asylum seekers were estimated approximately 124,298 and 110,764, respectively (TRC, 2016).

TRC is one of the main supporting organizations in Turkey working on relief operations for long periods of time and has many years of experience. TRC has various responsibilities in different areas including blood services, national disaster management, international programs and social services. Within the scope of Syrian Humanitarian Relief Operation, TRC has vast duties and responsibilities which can be categorized into two main groups based on the location of the refugees it serves. For Syrian refugees who live in the camps, TRC has been responsible for the fulfillment and distribution of basic humanitarian needs (i.e. tents, food, hygiene and medical supplies, etc.), supporting the workforce (i.e. educators, health officers, etc.) and procurement of side missions such as transportation and psycho-social support services.

The activities stated above are carried out in the 25 refugee camps established in Turkey, in 10 different cities. Out of 25 refugee camps, 17 are in the form of tent city, whereas 8 of them are container cities. The refugee camps are hosting an estimated 254,497 people. The spread of the refugee camps in Turkey can be seen on the map given in Figure 2.

\section{Refugee camp management}

The recent study by Jahre et al. (2018) analyzes the refugee camps from three different perspectives: time, space and resource. Time dimension considers the span of the camp as temporary or long term. Space dimension focuses on the interconnectedness of the camps with the local community. Finally, the resource dimension highlights the direction of the resource flow: one way (the refugees only consume) or two way (the refugees contribute in the local economy). We follow and build on this work while stressing the need for OR approaches and tools. As our analysis is based on Turkish case, the main framework will be directly suitable to a more traditional camp management according to the categorization of

Figure 2.

Refugee camps in Turkey, as of October 2016 TRC

presentation

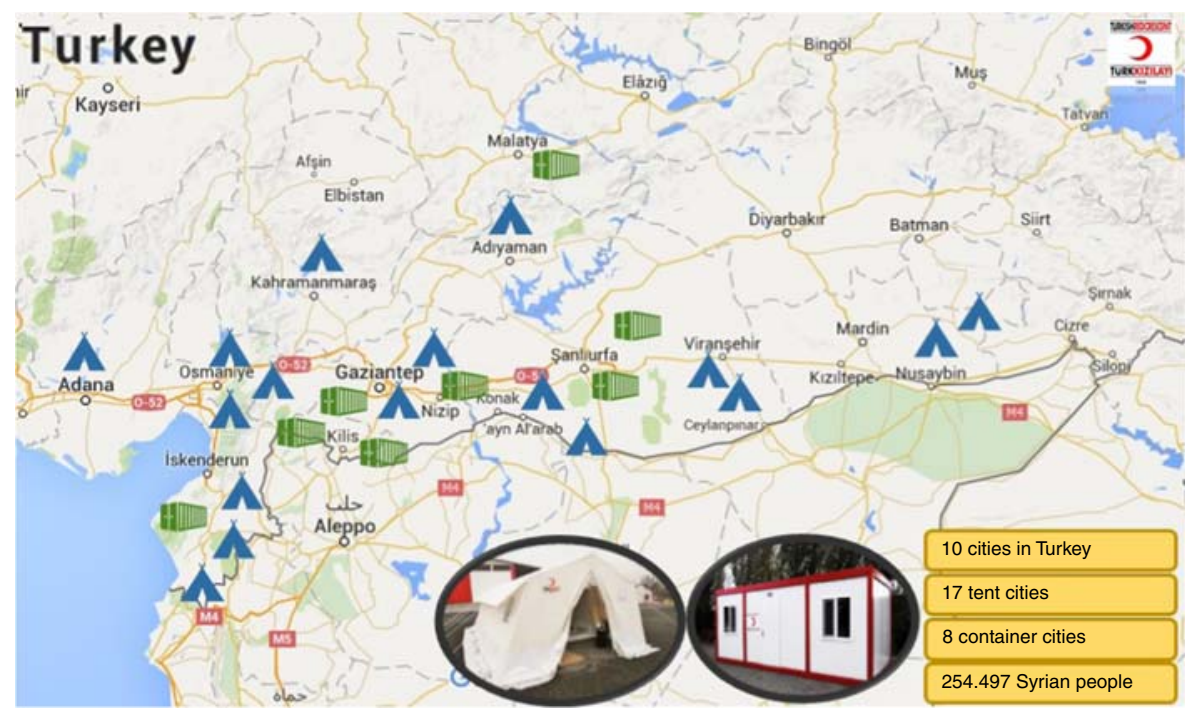

Source: TRC (2016) 
Jahre et al. (2018). However, our framework can easily be adapted to other approaches by defining the sets and parameters appropriately, as will be detailed in the sequel.

We define the refugee camp management as the entire process which begins with deciding to establish a refugee camp and continues as long as the conflict remains. We analyze the refugee camp management in two phases: establishment and administration. Establishment phase involves strategical and one-time decisions, and administrative phase involves tactical and operational decisions that require periodical planning as long as a refugee camp serves. The camp locations are usually selected based on the availability criteria and once the location is set the rest of the decisions are made. This may result in unnecessarily high infrastructure and administrative costs as well as high disutility from different parties involved. However, a pre-planned approach which considers all the related issues simultaneously would definitely improve those measures. Thus, in this study, we propose a unifying decision-making model that also considers the resulting infrastructure and administrative decisions during the establishment phase.

\section{Establishment phase}

Once the decision of building a camp for refugees is made, the first step is determining the location and the size (capacity) of the camp. At the very beginning, potential areas at an adequate size for the camp are determined. The ground study and infrastructure works of the sites where the camps will be established are performed. The candidate camp locations should be selected in convenient areas for connecting electricity, water and sewage networks to the city network, if possible. If the areas have no or inadequate electricity and water infrastructure, the necessary infrastructure works should be performed.

As depicted in Figure 3, the establishment phase involves two main design problems: the infrastructure design and the final camp design. The infrastructure design problem involves

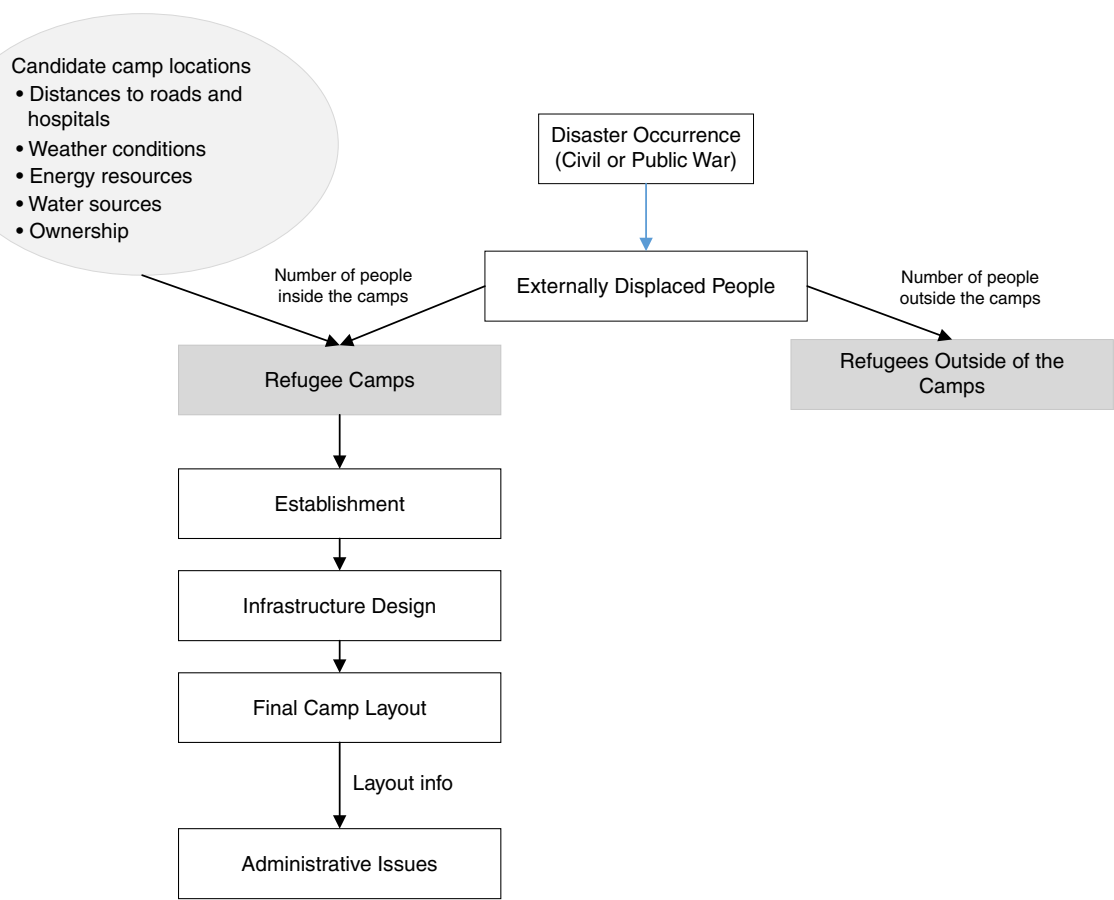

The refugee camp management

Figure 3.

Overview of refugee camp management framework 
JHLSCM

9,2

the decision and designs of the clean and sewage water, energy and road networks. The final camp design problem involves the detailed design decisions of the layout including the common facilities like kitchens, bathrooms, tent blocks, etc. These two designs are interrelated with each other, and thus, decisions on one affect the decisions on the other. For example, in order to design the sewage network, one needs the locations of kitchens, bathrooms, etc., which will be determined at the final camp layout. On the other hand, finalizing the camp layout decisions would require the definite knowledge of the infrastructure decisions.

In order to be able to make the infrastructure decisions without the exact knowledge of the camp layout, we propose a draft "block design" concept which would include aggregate level requirements. We remark here that, the block that we refer to is more general than its traditional use (Kennedy, 2008). We do not put restrictions on the places and the use of the blocks. The decision maker can control the design according to the situation and her preferences. Draft design considers the layout in forms of blocks where each block would represent a group of residential tents, common use areas or any combination like in the community based design (see Kennedy, 2008 for more details). That is, if the aim of the designer is habitat creation for long-term residency, then it can still be achieved through adjusting the definition of a block. For example, a small neighborhood that involves housing units, recreation areas and other shared facilities can also be defined as a block. Then, one can, for example, ensure that each "block" will have at least one recreation area, one kindergarten, etc., through constraints. In that sense, the mathematical modeling framework will provide sufficient flexibility to the decision makers.

The handbooks available in the literature for refugee camp and/or shelter sites are actually providing guides for different types of draft designs. In those guides, based on the size of the camp, the size and number of the common areas like kitchens, the minimal accessibility levels for public services (like reaching water source or a health clinic) and the minimum distance that must be kept between each pair of shelters are provided (The Sphere Project, 2011; UNHCR, 2007; Department of the US Air Force, 2000; Kennedy, 2004). Of course, the criteria and constraints to be considered will be different for health and waste management problems. For healthcare service provision, the main decisions in the establishment phase will include locations and the scales of the facilities to be located, while ensuring fair and easy access. On the contrary, in waste management, the service should be provided in such a way that the dump sites and any hazardous facilities should not endanger the daily life and this triggers the anti-closeness criteria. Again, all these problems are of multi-criteria nature, involving potentially conflicting criteria. To take another example, locating a dump site would include concerns on distance and fairness. The site should not be too far away from the camp, as otherwise, it would lead to high transportation costs. However, as this is an obnoxious facility location problem, one should also ensure that at least a certain level of distance is kept between any residential point and the facility. Moreover, there are fairness issues to be considered: a solution subjecting some population groups to much higher risks than the others would not be acceptable. Such issues that arise in the refugee camp context have the potential to lead to interesting OR problems that the researchers can focus on, hence would contribute to enhancing the OR practice.

In this paper, we propose a general framework and a unifying decision-making model for the refugee camp management problem which involves the site selection, establishment and operational decisions in an interrelated manner. We manage to handle the interactions of decisions at different levels by utilizing the "block" concept. Considering the fact that site selection is the most strategic decision, we build our unifying model on the site decisions. Each site alternative can be considered in the form of blocks in which different facility types and residential units could be established. Note that, the suitability of a facility type to be built at a block would depend on the particular site decision and we assume that this information could be available beforehand for each alternative location. 


\subsection{General model}

Let $M=\{1, \ldots, m\}$ denote the potential sites for refugee camps. Note that determining this set of potential camp locations is a special type of multiple-criteria decision-making problem (Farahani et al., 2010) in itself. Information on the candidate camp locations such as distances to roads or local hospitals, local energy and water network availability and other factors (e.g. weather conditions or ownership of the land) will be used in determining the candidate camp locations. For each $i \in M$, we will have a set of alternative capacity decisions and block structures, which will be based on the geographical structure of the location. Let $F T=\{1, \ldots, n f\}$ denote the set of facility types that need to be established in a camp. We define Type 1 as the residential areas, and $\{2, \ldots, n f\}$ will denote the rest like kitchens, bathrooms, social areas, etc. Each $f \in F T$ will have specific size information in terms of blocks. The number of facilities to be established, like the number of bathrooms, social areas, etc., will depend on the capacity decision, which will be determined alongside the location decision.

While determining the set of alternative facility types $(F T)$, one should consider the fact that refugee camps may last long. Hence, in addition to the infrastructural facilities, refugee camp management should consider public services which at least should include healthcare, education and security facilities. In addition to these, religious facilities, social activity centers (i.e. playgrounds, sports fields, multi-purpose areas, TV/internet halls, etc.) and administrative facilities (i.e. interpreting offices, registration, etc.) can also be considered. A commercial zone/plaza may even be planned which may include grocery stores, pharmacies, banks and/or ATMs, etc. (AFAD, 2014). An overall list of the necessary facilities can be seen in Figure 4.

We now define a variable indicating the location and capacity decisions of the camp as:

$$
X_{i}^{c}=\left\{\begin{array}{ll}
1, & \text { if location } i \text { is chosen with capacity } c \\
0, & \text { otherwise }
\end{array} .\right.
$$

Note here that, the location decision $i \in M$ actually corresponds to an area which we further partition into blocks. Thus, for each $i \in M$ and capacity decision, we have a set of blocks $B_{i}=\left\{1, \ldots, n b_{i}\right\}$. The number of blocks and the suitability of any block for any facility type is a function of the location and the capacity. That is, for each facility type $f \in F T$, we have a list $L_{f}\left(X_{i}^{c}\right)$ which consists of the indices of suitable blocks. We now define a new variable which will determine whether a facility type is built on a block or not:

$$
F_{f}^{b}= \begin{cases}1, & \text { if facility type } f \text { is located at grid (block) } b \\ 0, & \text { otherwise }\end{cases}
$$

for all $f \in F T$ and $b \in L_{f}\left(X_{i}^{c}\right)$.

In Figure 5, we provide a detailed example layout of one of the neighborhoods of a refugee camp in Turkey. The usage of block concepts can easily be observed in this example. Note that this is just an example design. The design can easily be adapted to reflect the preferences of the decision maker, if any. Kennedy (2008) discusses many different

\begin{tabular}{|c|c|c|c|c|c|}
\hline Shelters & $\begin{array}{l}\text { Kitchen and } \\
\text { Cafeteria }\end{array}$ & $\begin{array}{l}\text { Social Activity } \\
\text { Centers }\end{array}$ & $\begin{array}{c}\text { Laundry/ } \\
\text { Dishwashing }\end{array}$ & WC/Baths & $\begin{array}{l}\text { Administrative } \\
\text { Facilities }\end{array}$ \\
\hline $\begin{array}{l}\text { Healthcare } \\
\text { Facilities }\end{array}$ & $\begin{array}{l}\text { Safety and } \\
\text { Security }\end{array}$ & $\begin{array}{l}\text { Transportation } \\
\text { Facilities }\end{array}$ & $\begin{array}{l}\text { Education } \\
\text { Facilities }\end{array}$ & $\begin{array}{l}\text { Religious } \\
\text { Facilities }\end{array}$ & $\begin{array}{l}\text { Commercial } \\
\text { Facilities }\end{array}$ \\
\hline
\end{tabular}
design concept like U-shaped, Wheel-Scope, Circular, etc.

Figure 4. Final camp facilities 


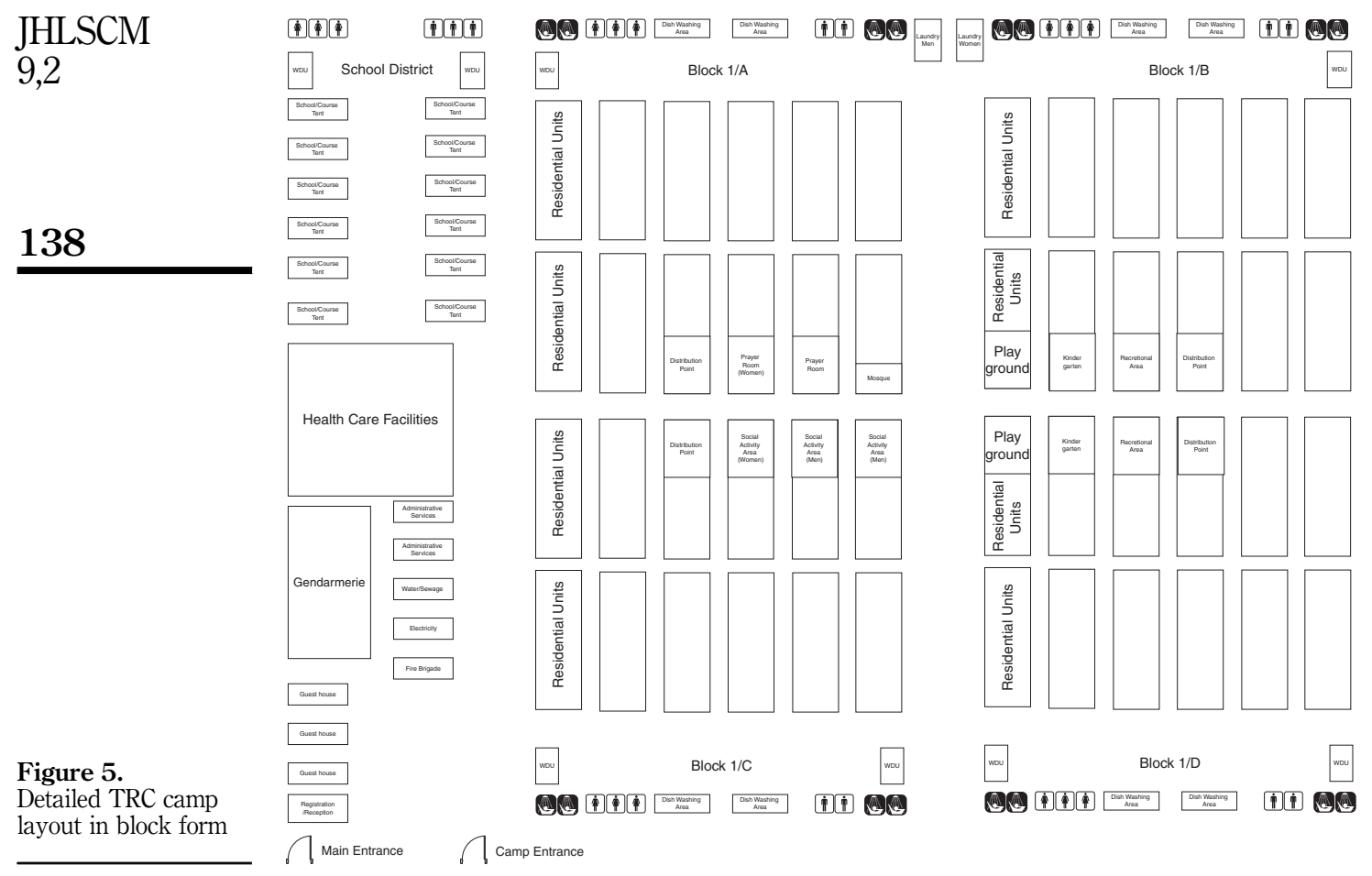

The interrelated decisions of site selection and facility-block assignment will actually determine the overall camp layout. Of course, these decisions would require an infrastructure design which will bring its own dynamics. The basic infrastructure needs are energy, and water and sanitation. The infrastructure design costs are actually the main drivers of the fixed establishment cost of the camps. These designs will be based on the local availability (of underground water, local sewage and energy sources) and the demand information (comes from $F_{f}^{b}$ decisions). The block assignment decisions will actually be driven by these infrastructure costs. Each particular network design will have its own cost functions and requirement specifications. However, they will share the same location and assignment decisions. Let $X$ and $F$ denote the set of feasible $X_{i}^{c} s$ and $F_{f}^{b} s$, respectively. Thus, the overall problem would look like:

$$
\min _{X_{i}^{c} \in X, F_{j}^{b} \in F} f\left(X_{i}^{c}, F_{f}^{b}, W D, E D\right)
$$

s.t.:

$$
\min _{W D \in W, E D \in E} C W N(W D)+C E N(E D),
$$

where $C W N(W D)$ represents the water and sewage network design cost function and $C E N$ (ED) represents the cost function for energy network designs where $W D \in W$ and $E D \in E$ represent the appropriate designs in the overall domains.

Figure 6 depicts the general structure of the interrelations. 


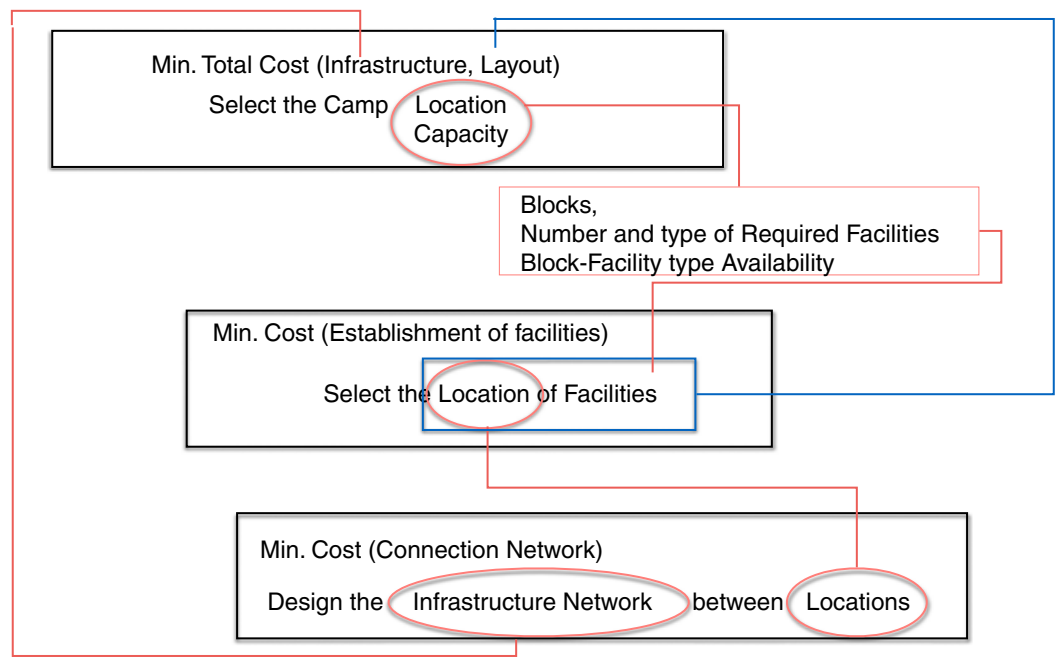

The refugee camp management

All the requirements of each facility type, like the size and number, their connectivity and minimal standards for service, will be considered during the overall minimization problem. For example, the blocks required for a hospital would need to be connected so that at the final layout enough space is left for the hospital, and thus, connectivity constraints need to be defined for the blocks assigned for such facilities. On another note, there will be service requirements between tent blocks and social service blocks. For example, minimal standards are defined for accessibility to water which actually specifies maximum allowable distance between tent blocks and water distribution units (WDUs). Geographical and financial constraints also shape these service requirements and hence the general design of a camp. For instance, in the IDP camp in Somalia, water requirement is met with common use water taps (TRC, 2015a) and there is one shared kitchen in the camp. However, water and kitchen are provided in each shelter in Syrian refugee camp, Kilis, Turkey (The New York Times Magazine, 2014). To take another example, while in the regions where water problems exist such as Somalia (TRC, 2015a), wells must be constructed, in other places where water infrastructure is accessible, there is not such a need for wells. Similarly, off-grid energy sources should be used as a supplier in the regions where local energy infrastructure is not accessible. The examples for different cases in different regions can be multiplied. Financial constraints also determine how the resources will be used. For example, electrical power should be used for different purposes such as security lighting, access lighting and operating water pumps around the camp. If time and funds permit, electrical power can then be provided to individual shelters. Providing adequate energy to every refugee helps them cook for themselves, gather with friends and visit the bathroom safer and easier. This is especially important for women and children.

In the subsequent section, we elaborate on the general requirements and structural dynamics of water and energy networks.

\subsection{Water and energy network designs}

Customarily, the main requirements for a water network design problem are: the locations and the demand of the users; potential supply points and capacities (connection to local network or utilization of wells); in case of well construction, the availability of the underground water network; and the geographical features such as pressure, height and the 
JHLSCM

9,2

slope of land. Thus, for a particular location and capacity decision giving the potential blocks and the subsequent decision of block-facility type assignments, the main inputs of the water network design problem have actually been finalized. Specifically, the block-facility type assignments, $\left(F_{j}^{b}\right)$ will provide the demand and supply information.

There may, of course, be additional facility types with no additional infrastructure requirements, specific to water design only, like WDUs. Note here that, wells cannot be considered under this heading since they do depend on other infrastructures, mainly energy.

Let $W F$ denote the set of these types of facilities. In water network design problem, the main decisions that should be made are where to locate the water network facilities in WF and how to design the required pipeline network. Thus, for the water network design we define two new variables:

$$
W F_{f}^{b}=\left\{\begin{array}{ll}
1, & \text { if water specific facility type } f \text { is located at block } b \\
0, & \text { otherwise }
\end{array},\right.
$$

$$
P L_{b 1, b 2}=\left\{\begin{array}{ll}
1, & \text { if a pipeline needs to be established between blocks } b_{1} \text { and } b_{2} \\
0, & \text { otherwise }
\end{array} .\right.
$$

With these settings, the water network design problem becomes: Given $X_{i}^{c}, F_{f}^{b}$

$$
\min _{W F_{f}^{b}, P L_{b 1, b 2}} C W N\left(W F_{f}^{b}, P L_{b 1, b 2}\right) .
$$

While locating facilities such as WDUs, the minimal requirements of The Sphere Project (2011) or Handbook for Emergencies (UNHCR, 2007) should also be considered. These standards dictate the maximum distances between service (WDU) and demand points (tents). These requirements and other types of technical constraints will determine the feasible region of this optimization problem.

Similarly, energy network design problem requires information on the demand level of the users and the nature of the supply (extension of a main grid, or an off grid, standalone structure). Given these, the energy network design problem will determine the necessity of the additional facility types like generation, storage and transmission units and the corresponding transmission lines.

Thus, the energy network design problem is: Given $X_{i}^{c}, F_{f}^{b}$

$$
\min _{E F_{f}^{b}, T L_{b 1, b 2}} E W N\left(E F_{f}^{b}, T L_{b 1, b 2}\right)
$$

where:

$$
E F_{f}^{b}= \begin{cases}1, & \text { if energy specific facility type } f \text { is located at block } b \\ 0, & \text { otherwise }\end{cases}
$$

and:

$$
T L_{b 1, b 2}=\left\{\begin{array}{ll}
1, & \text { if a transmission line needs to be established between blocks } b_{1} \text { and } b_{2} \\
0, & \text { otherwise }
\end{array} .\right.
$$

Of course, the energy and water problems cannot be solved separately as they both require and also make the decisions of the facility type and block assignments. In order to get the 
global optimum for the layout design, one needs to consider these two problems simultaneously. Thus, the optimization framework in Equation (3) is actually:

$$
\min _{X_{i}^{c} \in X, F_{i} \in F} f\left(X_{i}^{c}, F_{f}^{b}, W F_{f}^{b}, P L_{b 1, b 2}, E F_{f}^{b}, T L_{b 1, b 2}\right),
$$

The refugee camp management

s.t.:

$$
\min _{W F_{f}^{b}, P L_{b 1, b 2} \in W, E F_{f}^{b}, T L_{b 1, b 2} \in E} C W N\left(W F_{f}^{b}, P L_{b 1, b 2}\right)+C E N\left(E F_{f}^{b}, T L_{b 1, b 2}\right) .
$$

In order to clarify the methodology, we now provide a small case for the refugee camps in the southern part of Turkey. Recall that, currently there are 25 camps (as given in Figure 2). All those 25 locations must have been selected from a larger set that also contains those 25 locations which constitutes the alternative locations set $M$. For each $i \in M$, there will be alternative capacity decisions like 10,000; 20,000; 50,000; and 100,000 habitants. Let us take one alternative location, say Nizip, from set $M$ which currently contains approximately 14,000 Syrians. For Nizip with the given capacity, we have the set $F T$ which contains the set of facilities to be opened (e.g. $F T=\{$ tents, WC, Bath, Kitchen, SocialArea, Mosque, ... $\}$ ). With the block structure of Nizip, and for each required facility type $f$, we can deduct $L_{f}$ (Nizip), which will consist of the indices of the blocks that are suitable for facility type $f$. Once these sets are defined, the minimization given in Equation (10) will determine the locations of each facility type with the required connections. Once the model is built and the problem parameters are determined, it can be solved using off-the-shelf optimization tools.

The water and energy sub-modules of the establishment phase that we have discussed mainly include distributing somewhat continuous resources to the usage points. Therefore, these two issues are crucial in the establishment phase. Once the networks are designed in a sufficient way, they will not bring significant operational challenges other than routine maintenance operations. However, other operational issues like safety and security, health and sanitation, aid distribution, transportation services, education and psycho-social activities constitute various decision-making problems that occur on a periodic basis. A detailed planning and consideration for such activities is also crucial as refugee camps may have to serve for many years. In the history, there are many examples of refugee camps that provide service for more than 20 years. Bosnia and Herzegovina, Sudan and Afghanistan can be the examples of long-servicing refugee camps (UNHCR, 2016d). In the next section we focus on these decisions under the refugee camp administration heading.

\section{Refugee camp administration}

Establishment phase includes infrastructure design for water and sanitation, and energy. These decisions along with the facility-block assignments lead to the final layout of the camp. Once the layout is finalized, administrative processes begin.

As stated before, administrative processes of a refugee camp have not received enough attention in the literature. McAdam (1987) studies the administration of refugee camps within a limited scope and focuses on issues like how to select management staff and other personnel of refugee camps. Cosgrave (1996) reviews the nature of decision making in emergencies and then suggests a simplified decision process model for emergency managers, exemplifying it with refugee emergencies. Cuny (1977) analyzes refugee camp planning and details management process under four titles: physical, social, health and administrative factors. Under the sub-title of physical factors, Cuny discusses issues related to site selection and planning. In the administrative factors section, he analyzes how a refugee camp should be run and by whom. 
JHLSCM

9,2

142
In this study, administrative issues of the refugee camp are examined under six sub-titles as safety and security, health and sanitation, education, psycho-social activities, aid distribution and transportation. Detailed refugee camp administrative issues chart can be seen in Figure 7. We believe that this figure can help OR practitioners detect areas that they can offer solutions in the refugee camp management context. This could be in the form of applying an established decision support methodology to these specific areas, which would contribute to the OR practice. The dynamics of the refugee camps could also make researchers introduce interesting and challenging problems to the OR literature, enhancing the OR theory, mainly in terms of applications.

In Table II, we give some example works from the OR literature considering problems that could be relevant in camp administration, which include books and articles in well-known OR journals. Although the list is not exhaustive, these references could act as an initial guide for practitioners and help them detect what OR can offer for the solution of their problem.

In each subsection below, we clarify and detail these decision-making problems and provide further references whenever possible.

\subsection{Safety and security}

Ensuring safety and security of the residents in a camp is one of the most crucial duties of camp administration. Likewise other sections, while designing the security systems of the refugee camps, minimal standards and requirements in the provided references (Jacobsen,

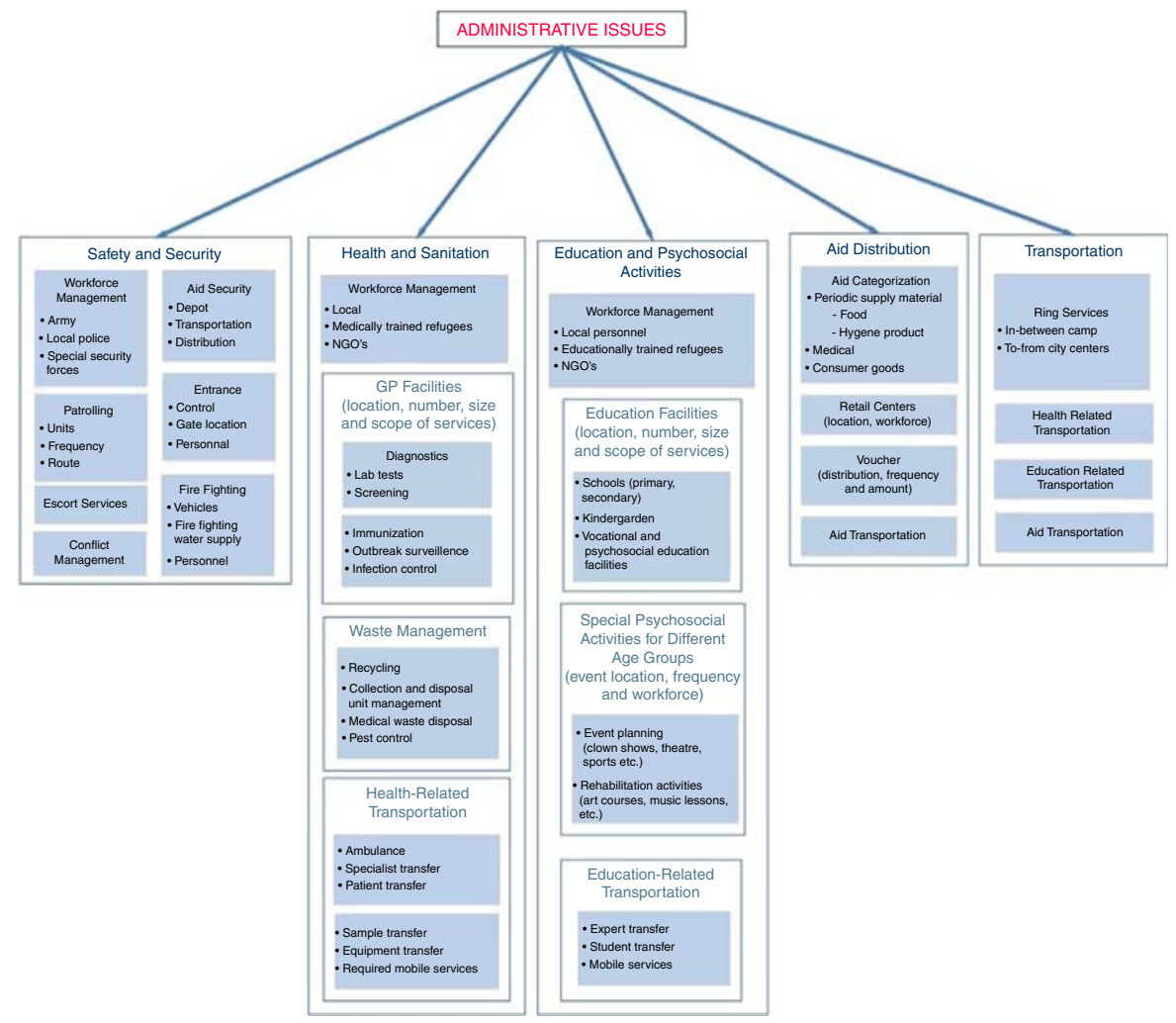

Figure 7.

Refugee camp administrative issues 


\begin{tabular}{|c|c|c|c|c|}
\hline Category & Subcategory & Problem & Example works & $\begin{array}{l}\text { e refugee } \\
\text { camp }\end{array}$ \\
\hline \multirow{4}{*}{$\begin{array}{l}\text { Safety and } \\
\text { security }\end{array}$} & \multirow{4}{*}{$\begin{array}{l}\text { Resource } \\
\text { allocation }\end{array}$} & Workforce scheduling & Ernst et al. (2004), Van den Bergh et al. (2013) & management \\
\hline & & Assignment & Pentico (2007) & \\
\hline & & Routing and transportation & Birge and Pollock (1989), Golden et al. (2008) & \\
\hline & & Patrolling & Barnhart and Laporte (2006) & \\
\hline \multirow{9}{*}{$\begin{array}{l}\text { Health and } \\
\text { sanitation }\end{array}$} & \multirow[t]{2}{*}{ Primary care } & Capacity planning & Brandeau et al. (2004), Rais and Viana (2011), & 143 \\
\hline & & Workforce scheduling & Ernst et al. (2004), Van den Bergh et al. (2013) & \\
\hline & \multirow[t]{2}{*}{$\begin{array}{l}\text { Specialist } \\
\text { care }\end{array}$} & $\begin{array}{l}\text { Scheduling for outsourced } \\
\text { care }\end{array}$ & Cayirli and Veral (2003) & \\
\hline & & Routing & $\begin{array}{l}\text { Barnhart and Laporte (2006), } \\
\text { Golden et al. (2008) }\end{array}$ & \\
\hline & \multirow[t]{3}{*}{$\begin{array}{l}\text { Preventive } \\
\text { care }\end{array}$} & Vaccination planning & & \\
\hline & & Screening planning & Shwartz (1978) & \\
\hline & & Transportation & Barnhart and Laporte (2006) & \\
\hline & \multirow{2}{*}{$\begin{array}{l}\text { Waste } \\
\text { management }\end{array}$} & Debris removal planning & Sahin et al. (2016), Ghiani et al. (2014) & \\
\hline & & Location (for related facilities) & Erkut et al. (2008) & \\
\hline \multirow{2}{*}{$\begin{array}{l}\text { Education and } \\
\text { psycho-social } \\
\text { activities }\end{array}$} & \multirow[t]{2}{*}{$\begin{array}{l}\text { Resource } \\
\text { allocation }\end{array}$} & Routing and scheduling & $\begin{array}{l}\text { Barnhart and Laporte (2006), } \\
\text { Golden et al. (2008) }\end{array}$ & \\
\hline & & Workforce planning & Ernst et al. (2004), Van den Bergh et al. (2013) & \\
\hline \multirow[t]{8}{*}{$\begin{array}{l}\text { Aid } \\
\text { management }\end{array}$} & \multirow[t]{5}{*}{$\begin{array}{l}\text { Supply } \\
\text { chain } \\
\text { management }\end{array}$} & $\begin{array}{l}\text { Warehouse design and } \\
\text { management }\end{array}$ & $\begin{array}{l}\text { Beamon (1998), Gu et al. (2010), Rouwenhorst } \\
\text { et al. }(2000)\end{array}$ & \\
\hline & & Location & Çelik et al. (2012) & \\
\hline & & Layout & Gu et al. (2007) & \\
\hline & & Material handling & Matson and White (1982) & \\
\hline & & Inventory management & Duran et al. (2011) & \\
\hline & Distribution & Relief logistics & Özdamar and Ertem (2015), Özdamar and & \\
\hline & & & $\begin{array}{l}\text { Demir (2012), Barnhart and Laporte (2006), } \\
\text { Golden et al. (2008) }\end{array}$ & $\begin{array}{r}\text { Table II. } \\
\text { Some OR problems }\end{array}$ \\
\hline & $\begin{array}{l}\text { Resource } \\
\text { allocation }\end{array}$ & $\begin{array}{l}\text { Workforce planning and } \\
\text { scheduling }\end{array}$ & Ernst et al. (2004), Van den Bergh et al. (2013) & $\begin{array}{l}\text { related to camp } \\
\text { administration }\end{array}$ \\
\hline
\end{tabular}

1999), should be considered. The managers should consider both conflict within residents and/or personnel and potential threats from outside of the camp. Thus, gates and checkpoints should be secured and patrolling units should be employed. Depending on the technological availabilities, surveillance systems can also be utilized.

In addition to the violence prevention, security of the in-kind donations is also of utmost concern. Thus, the storage areas should also be secured and escort services during the transportation of donation should be planned. To take an example, in Somalia refugee camp, security is responsible for fetching aid items safely (TRC, 2015a). Escort service requirement is not limited to aid transportation, but can also be used for other transportation services required for the camp residents, personnel and volunteers.

Another issue that can endanger the camp safety is the outbreak of fire. The risk of fire is even more pronounced since the living areas are mainly tents which are more vulnerable to fire, residents may use fire-pits for cooking and heating, and the potential of spreading is high. Thus, camp management should take necessary measures and employ enough personnel and equipment to respond to any such emergencies.

The prominent OR problems related to safety and security are mainly workforce selection among the alternatives and assignment. Possible alternatives for security 
JHLSCM

9,2

144

personnel include army, gendarmerie, local police or special security forces. Once the crew is determined, the frequency of visits and the tours whenever applicable should also be clarified, which also brings routing and scheduling problems.

\subsection{Health and sanitation}

Under health and sanitation headline, the main topics to be considered include healthcare service and waste management design.

There are four main categories of scope of health services which are emergency, primary healthcare, preventive and specialized care. The role of public health in overall disaster management is explained by Noji (2005), which includes discussion on refugee health from the epidemics, immunization and nutrition perspectives.

According to the scope of healthcare to be provided in the camps, different health services can be offered to refugees. For instance, since risk of epidemics is high in crowded communities like refugee camps, preventive care such as periodical vaccinations can be provided, leading to interesting vaccination planning problems (for an example vaccination planning model, see Jacobson et al., 1999). To take another example, if diagnostics services are provided, lab tests and screenings for different diseases can be conducted which may require medical transportation to the dedicated hospitals. On the other hand, some healthcare services should be provided in any case, independent of the scope of services. In addition, camp health managers should be aware of the infection risks, and conduct infection control and outbreak surveillance activities. Specialists as psychologists and psychiatrists should also support refugees.

The scope of health services determines the capacity of healthcare facilities and the range of expertise of the doctors. If a healthcare facility is not set up in the camp or if in-house healthcare facilities are inadequate or can only provide the basic service in a limited scope, mobile or external support may be used as backup solutions to provide health services at the required level. Periodic dermatologist visits to Syrian Refugee Camps of Turkey is an example for this.

Waste management is also crucial to ensure adequate hygiene level and to prevent any health-related issues such as epidemics. The waste management process can even start from debris cleaning, which may be an issue (at the camps located in conflict zones), and will include classical municipal waste management issues such as land sites for wild dumping, recycling options, bone grinding, pest control and handling medical waste, which should definitely be managed apart from the municipal waste. To ensure adequate sanitation, collection and disposal of daily garbage should also be taken into consideration. Trash cans must be placed in specific points in the camps, and cleaning workers and waste collection vehicles should provide cleaning services regularly.

In the literature, Klumpp et al. (2015) study waste management and recycling in refugee camps. They provide a classification of waste according to different type of disasters including refugee crisis and they have proposed some solutions to reuse the waste. Garfi et al. (2009) analyze waste management of Saharawi refugee camp using the method of analytical hierarchy process. Waste management of refugee camps and municipal waste management are somewhat similar to each other. Thus, studies addressing the municipal waste management can also be good references for the refugee camp waste management problem (Tchobanoglous et al., 1993).

Monitoring the quality of the healthcare services provided is also an important issue. Data on certain clinical indicators can be kept to assure that the services are of good quality. There are studies that evaluate healthcare services at refugee camps (see Sahlool et al., 2012 for an example at Syrian refugee camps in Turkey). A number of good practice guidelines are also available for healthcare service planners and act as a guide for health assessment, planning, monitoring and surveillance by listing minimum standards and essential healthcare programs (Frontieres, 1994; UNHCR, 2007; The Sphere Project, 2011). 
There are also a number of health-related transportation arrangement requirements in the camp. If comprehensive healthcare cannot be provided to refugees, ambulances or helicopters should be provided in the camps for patient transfer to the hospitals in emergency situations. The organization of the shuttles that will carry specialists to the camps need to be planned considering the frequency of visit. Likewise, if medical analysis services will be provided to refugees, samples should periodically be carried to the labs for testing. Periodical equipment transfer may also be needed. Moreover, if an on-site pharmacy is not available, medicine should be transported to the camp.

Health administration leads to a number of OR problems such as workforce allocation and scheduling (of doctors or nurses) and any related transportation problems, like periodic routing problem for scheduling the visits of specialists. The periodic tests and preventive care vaccinations also lead to scheduling and routing problems. An emergency situation creates a logistics problem of how to move the patient to the hospital. Capacity planning that ensures an adequate service level is also among the OR problems that need to be tackled in this heading.

\subsection{Education and psycho-social activities}

Due to the fact that refugee camps can serve long periods of time, the camp management should consider running educational facilities serving all age groups, if possible. Language barrier is one of the main reasons for having education facilities within the camps. Depending on the regulations of the host country, native teachers from the residents could be utilized in these schools which would also help in providing occupation and preventing language barrier issues. If in-house education option is not sufficient, then local facilities in the surrounding area of the hosting municipality may be utilized. This option brings additional concerns regarding the transportation and security of the students.

In addition to basic educational services, the camp management should also plan certain activities for potential occupational purposes like carpentering, sewing, computer usage, etc. These types of courses would help residents to gain new skills which could be utilized as occupation in daily camp life, as well as providing psycho-social support for rehabilitation.

Considering the everyday life of camp residents, planning social events such as clown shows, theater, movie nights, sports events and concerts is important. Depending on the availability of the residents and/or volunteers, certain art courses (painting, marbling, drama, etc.) can also be planned, which, again is helpful for psychological recovery. These activities are utmost concern for kids considering their vulnerability. Professional help by social workers, psychologists, sociologists and pedagogues should be provided for the rehabilitation of kids in the camps (TRC, 2008).

In Turkey, Ministry of Family and Social Policies has been working on psycho-social rehabilitation by means of its psychologists, sociologists and pedagogues. Senior instructors perform activities in kindergartens to contribute to the personal developments of kids and to provide psycho-social support.

The OR problems involved in the education activities are analogous to their counterparts encountered in urban education system. Workforce planning (local personnel of country of asylum, educationally trained refugees or staff of NGO's), scheduling and assignment are the main topics to be considered. For the outsourced events, event choice and location selection, resource planning and frequency determination are the main decisions that can utilize OR tools.

\subsection{Aid management}

Aid management is certainly one of the crucial aspects in camp management. The challenge of aid management is mainly due to both supply and demand uncertainty in terms of type, amount and time of the aid items. The demand will be shaped based on the
The refugee camp management 
JHLSCM

9,2

requirements of the camp residents and can include wide range of items not restricted to nutritional requirements and daily clothing but also diapers, baby food and also health and hygiene products.

On the other hand, especially in the beginning, supply is highly uncertain and it is not derived by the demand. There are many examples (see book of Tomasini and Van Wassenhove, 2009) of unneeded material blocking the supply chain of the necessary items like bicycles in Japan tsunami or bikinis and swimsuits in Haiti earthquake.

Thus, the first issue to be handled in aid management appears to be demand determination in order to drive the supply as much as possible. This will not only help in balancing the demand and supply, but also contribute toward an efficiently running supply chain.

Customarily NGOs are very active in calling for required materials in camps. Each one runs different campaigns based on the qualifications of their specific NGO. Usually, information flow between NGOs is not very well-established, and thus, camp management should coordinate the aid coming from these units in order to use these key resources efficiently and effectively (Altay and Pal, 2014).

Once the aid starts to flow through the camp, the issue of storing, securing and distribution becomes apparent. Especially, during the storage, the perishability nature of the aid material should be taken into account, and thus, the camp management should also consider warehouse management issues including the warehouse design decisions, allocation of the material within the layout and warehouse operating policies such as first-in first-out.

Obviously, an effective warehouse management would require a database system that includes all related and necessary information including the type, amount and shelf life of the aid. The database should both register entry of the aid and its delivery to its destination. The destination can either be a family in a tent or common use facilities like healthcare facilities, education facilities and main kitchen. Depending on the geographical dispersion and the location of the depot in the camp, camp management may decide to operate additional small-sized distribution units. These distribution units will customarily be located in the plazas so that residents can reach easily and will distribute frequently used items such as diapers, shampoo and dry food for the tents running their own kitchens. Security, storage and data management are also relevant for these distribution units. The synchronization of the databases of the distribution units with the main warehouse(s) is crucial.

The distribution of the required aid material to common use facilities will usually be from the main warehouses and the required transportation will be discussed in Section 5.5. All related security issues are discussed in Section 5.1.

As evident, there are many OR problems faced during the aid management. These include the problems such as location (in determining the location of the warehouse and distribution units), workforce planning and allocation (while coordinating NGOs) and routing for the distribution of aid to common use facilities.

In addition to previously discussed problems, aid management requires some additional OR problems such as layout and material handling and inventory management. Combination of these decisions are of course part of the overall supply chain of the camp, and there are studies in the literature which focus on certain parts of these supply chain management problems (Van Wassenhove, 2006; Beamon and Balcik, 2008; Stauffer et al., 2016; Bhattacharya et al., 2014; Balcik et al., 2008, 2010; Beamon, 2008; Spiliotopoulou et al., 2015).

Recently, there are different applications of voucher systems, which are very good means for diverting in-kind donations toward cash. As an example, TRC distributes cash cards to the Syrian refugees in Turkey (TRC, 2015b) in the scope of E-Voucher Program (WFP/TRC Food Card). To take another example, in a Syrian refugee camp in Jordan, UNHCR (2016e) provides cash assistance to refugees in the camps through Cash on Wheels project, in which, 
there is a car carrying ATM machine through the camp. In the literature, Besiou and Van Wassenhove (2015) discuss food or cash distribution in the scope of socially responsible operations. The design of such voucher systems will define new OR problems to the literature which involves decisions related to frequency and amount determination, and distribution and monitoring.

\subsection{Transportation services}

In the previous sections for each heading, several issues related to transportation have already been discussed. Section 5.2 details transportation needs for health and sanitation activities, which include transferring patients to main hospitals outside the camp, shuttle services for periodic visits of specialists, collection and distribution services of specimen, blood and medicine. Similar transportation activities will also be required for educational and psycho-social purposes. These may include shuttle services for teachers, transfer of pupils, and if necessary, psychologists. Thus, camp management should ensure that these periodical trips could be carried out.

Refugees may desire to go outside of the camp for different reasons such as visiting their relatives living in other refugee camps. For such purposes, periodical ring services can be provided between different camps.

Transportation services will also be required between the warehouse(s), the distribution centers and common service areas like healthcare and educational facilities. Planning the frequencies of these transportation activities is also crucial.

In its essence, transportation is one of the basic OR problems. Thus, there are many variants that can be defined which would be relevant in transportation services of camp management. Classical location-allocation problems, routing problems and periodic routing problems are among the OR problems that will definitely be seen in camp operations. One may even define new variants to those classical OR problems by considering the detailed operational dynamics of the refugee camps.

\section{Conclusion}

In this study, our main motivation is to provide an overall framework for the general refugee camp management problem. The related literature is very scarce and diverse. Utilizing TRC's know-how from the field, we aim to link the OR literature with the different phases of camp management. We differentiate the decisions based on their levels as strategic (constituting the establishment phase), tactical and operational which are discussed in the administration phase.

Actually, refugee camp management is a problem that can happen in a diversity of regions, each with different settings and requirements. Thanks to TRC's expertise on camp management in many regions including Somalia, Iraq, Bangladesh, etc., in addition to the Turkish camps, we propose a general framework that could be of use to practitioners as well as academicians. The proposed framework will constitute an example for countries of asylum and national or international NGOs to manage the refugee camps efficiently. We also highlight main challenges and dynamics of the decision-making problems encountered in different parts of the proposed framework, which may constitute many different problems to the OR literature, each of which can open new venues for future research.

\section{References}

AFAD (2014), "Syrian guests in Turkey", available at: www.afad.gov.tr/Dokuman/TR/99-2014061912 71-syrian-guests.pdf (accessed June 23, 2016).

Altay, N. and Pal, R. (2014), "Information diffusion among agents: implications for humanitarian operations", Production and Operations Management, Vol. 23 No. 6, pp. 1015-1027. 
JHLSCM

9,2

Balcik, B., Beamon, B.M. and Smilowitz, K. (2008), "Last mile distribution in humanitarian relief", Journal of Intelligent Transportation Systems, Vol. 12 No. 2, pp. 51-63.

Balcik, B., Beamon, B.M., Krejci, C.C., Muramatsu, K.M. and Ramirez, M. (2010), "Coordination in humanitarian relief chains: practices, challenges and opportunities", International Journal of Production Economics, Vol. 126 No. 1, pp. 22-34.

Barnhart, C. and Laporte, G. (2006), Handbooks in Operations Research and Management Science: Transportation, Vol. 14, Elsevier, Amsterdam.

Beamon, B.M. (1998), "Supply chain design and analysis: models and methods", International Journal of Production Economics, Vol. 55 No. 3, pp. 281-294.

Beamon, B.M. (2008), "Sustainability and the future of supply chain management", Operations and Supply Chain Management, Vol. 1 No. 1, pp. 4-18.

Beamon, B.M. and Balcik, B. (2008), "Performance measurement in humanitarian relief chains", International Journal of Public Sector Management, Vol. 21 No. 1, pp. 4-25.

Besiou, M. and Van Wassenhove, L.N. (2015), "Addressing the challenge of modeling for decision-making in socially responsible operations", Production and Operations Management, Vol. 24 No. 9, pp. 1390-1401.

Bhattacharya, S., Hasija, S. and Van Wassenhove, L.N. (2014), "Designing efficient infrastructural investment and asset transfer mechanisms in humanitarian supply chains", Production and Operations Management, Vol. 23 No. 9, pp. 1511-1521.

Birge, J. and Pollock, S. (1989), "Modelling rural police patrol", Journal of the Operational Research Society, Vol. 40 No. 1, pp. 41-54.

Brandeau, M.L., Sainfort, F. and Pierskalla, W.P. (2004), Operations Research and Health Care: A Handbook of Methods and Applications, Vol. 70, Springer Science + Business Media, Dordrecht.

Cayirli, T. and Veral, E. (2003), "Outpatient scheduling in health care: a review of literature", Production and Operations Management, Vol. 12 No. 4, pp. 519-549.

Çelik, M., Ergun, O., Johnson, B., Keskinocak, P., Lorca, A., Pekgtin, P. and Swann, J. (2012), "Humanitarian logistics", in Mirchandani, P. (Ed.), New Directions in Informatics, Optimization, Logistics, and Production, INFORMS, pp. 18-49.

Cosgrave, J. (1996), "Decision making in emergencies", Disaster Prevention and Management, Vol. 5 No. 4, pp. 28-35.

Cuny, F.C. (1977), "Refugee camps and camp planning: the state of the art", Disasters, Vol. 1 No. 2, pp. 125-143.

Department of the US Air Force (2000), Refugee Camp Planning and Construction Handbook, Department of the US Air Force, Washington, DC, available at: http://webapp1.dlib.indiana. edu/virtuaLdis\%5elibrary/index.cgi/821003/FID581/pubs/af/10/afh222v22/afh10-222v22.pdf (accessed June 23, 2016).

Duran, S., Gutierrez, M.A. and Keskinocak, P. (2011), "Pre-positioning of emergency items for care international", Interfaces, Vol. 41 No. 3, pp. 223-237.

Erkut, E., Karagiannidis, A., Perkoulidis, G. and Tjandra, S.A. (2008), "A multicriteria facility location model for municipal solid waste management in North Greece", European Journal of Operational Research, Vol. 187 No. 3, pp. 1402-1421.

Ernst, A.T., Jiang, H., Krishnamoorthy, M. and Sier, D. (2004), "Staff scheduling and rostering: a review of applications, methods and models", European Journal of Operational Research, Vol. 153 No. 1, pp. 3-27.

Eurostat (2018), “Asylum statistics”, available at: http://ec.europa.eu/eurostat/statistics-explained/ index.php (accessed March 28, 2018).

Farahani, R.Z., SteadieSeifi, M. and Asgari, N. (2010), "Multiple criteria facility location problems: a survey", Applied Mathematical Modelling, Vol. 34 No. 7, pp. 1689-1709.

Frontieres, M. (1994), Public Health Engineering in Emergency Situations, Medecins Sans Frontieres, Paris. 
Garfi, M., Tondelli, S. and Bonoli, A. (2009), "Multi-criteria decision analysis for waste management in Saharawi refugee camps”, Waste Management, Vol. 29 No. 10, pp. 2729-2739.

Ghiani, G., Lagana, D., Manni, E., Musmanno, R. and Vigo, D. (2014), "Operations research in solid waste management: a survey of strategic and tactical issues", Computers \& Operations Research, Vol. 44, pp. 22-32.

Golden, B.L., Raghavan, S. and Wasil, E.A. (2008), The Vehicle Routing Problem: Latest Advances and New Challenges, Vol. 43, Springer Science + Business Media, New York, NY.

Gu, J., Goetschalckx, M. and McGinnis, L.F. (2007), "Research on warehouse operation: a comprehensive review”, European Journal of Operational Research, Vol. 177 No. 1, pp. 1-21.

Gu, J., Goetschalckx, M. and McGinnis, L.F. (2010), "Research on warehouse design and performance evaluation: a comprehensive review”, European Journal of Operational Research, Vol. 203 No. 3, pp. 539-549.

Jacobsen, K. (1999), “A safety-first approach to physical protection in refugee camps”, available at: http://web.mit.edu/cis/www/migration/pubs/rrwp/4_safety.html (accessed April 25, 2017).

Jacobson, S.H., Sewell, E.C., Deuson, R. and Weniger, B.G. (1999), “An integer programming model for vaccine procurement and delivery for childhood immunization: a pilot study”, Health Care Management Science, Vol. 2 No. 1, pp. 1-9.

Jahre, M., Kembro, J., Adjahossou, A. and Altay, N. (2018), “Approaches to the design of refugee camps: an empirical study in Kenya, Ethiopia, Greece, and Turkey”, Journal of Humanitarian Logistics and Supply Chain Management, Vol. 8 No. 3, pp. 323-345.

Kennedy, J. (2004), “Towards a rationalisation of the construction of refugee camps”, master's thesis, Katholieke Universitiet Leuven, Leuven.

Kennedy, J. (2008), "Structures for the displaced: service and identity in refugee settlements", PhD thesis, Delft University of Technology (TU Delft), Delft.

Klumpp, M., Leeuw, S., Regattieri, A. and Souza, R. (2015), Humanitarian Logistics and Sustainability, Springer, Dordrecht.

McAdam, R. (1987), "Engineering management in refugee camps”, Disasters, Vol. 11 No. 2, pp. 110-112.

Matson, J.O. and White, J.A. (1982), “Operational research and material handling”, European Journal of Operational Research, Vol. 11 No. 4, pp. 309-318.

Noji, E.K. (2005), "Public health issues in disasters", Critical Care Medicine, Vol. 33 No. 1, pp. S29-S33.

Özdamar, L. and Demir, O. (2012), “A hierarchical clustering and routing procedure for large scale disaster relief logistics planning”, Transportation Research Part E: Logistics and Transportation Review, Vol. 48 No. 3, pp. 591-602.

Özdamar, L. and Ertem, M.A. (2015), "Models, solutions and enabling technologies in humanitarian logistics”, European Journal of Operational Research, Vol. 244 No. 1, pp. 55-65.

Pentico, D.W. (2007), “Assignment problems: a golden anniversary survey”, European Journal of Operational Research, Vol. 176 No. 2, pp. 774-793.

Rais, A. and Viana, A. (2011), "Operations research in healthcare: a survey”, International Transactions in Operational Research, Vol. 18 No. 1, pp. 1-31.

Rouwenhorst, B., Reuter, B., Stockrahm, V., van Houtum, G.-J., Mantel, R. and Zijm, W.H. (2000), "Warehouse design and control: framework and literature review", European Journal of Operational Research, Vol. 122 No. 3, pp. 515-533.

Sahin, H., Kara, B.Y. and Karasan, O.E. (2016), "Debris removal during disaster response: a case for turkey”, Socio-Economic Planning Sciences, Vol. 53, pp. 49-59.

Sahlool, Z., Sankri-Tarbichi, A. and Kherallah, M. (2012), "Evaluation report of health care services at the Syrian refugee camps in Turkey”, Avicenna Journal of Medicine, Vol. 2 No. 2, pp. 25-28.

Shwartz, M. (1978), “A mathematical model used to analyze breast cancer screening strategies”, Operations Research, Vol. 26 No. 6, pp. 937-955.

The refugee camp management 
JHLSCM

9,2

Smith-Daniels, V.L., Schweikhart, S.B. and Smith-Daniels, D.E. (1988), "Capacity management in health care services: review and future research directions", Decision Sciences, Vol. 19 No. 4, pp. 889-919.

Spiliotopoulou, E., Donohue, K. and Gtirbtiz, M.C. (2015), "Information reliability in supply chains: the case of multiple retailers", Production and Operations Management, Vol. 25 No. 3, pp. 548-567.

Stauffer, J.M., Pedraza-Martinez, A.J. and Van Wassenhove, L.N. (2016), "Temporary hubs for the global vehicle supply chain in humanitarian operations", Production and Operations Management, Vol. 25 No. 2, pp. 192-209.

Tchobanoglous, G., Theisen, H. and Vigil, S. (1993), Integrated Solid Waste Management: Engineering Principles and Management Issues, McGraw-Hill, New York, NY.

The New York Times Magazine (2014), "How to build a perfect refugee camp", The New York Times Magazine, February 13, available at: www.nytimes.com/2014/02/16/magazine/how-to-build-aperfect-refugee-camp.html?_r=1 (accessed June 23, 2016).

The Sphere Project (2011), "Humanitarian charter and minimum standards in humanitarian response", available at: www.ifrc.org/PageFiles/95530/The-Sphere-Project-Handbook-20111.pdf (accessed June 23, 2016).

Tomasini, R. and Van Wassenhove, L. (2009), Humanitarian Logistics, Palgrave Macmillan, Basingstoke.

TRC (2008), "Psikososyal Destek Uygulama Rehberi”, Turk Kizilayi, Afet Mudahale ve Yardimlar Yonetimi Bolumu, Ankara, May.

TRC (2015a), "Reports of Somalia Humanitarian Aid", available at: www.kizilay.org.tr/Upload/Dokuman/ Dosya/03101983_-2015-somali-insani-yardim-operasyonu.pdf (accessed June 23, 2016).

TRC (2015b), "Reports of Syria Humanitarian Aid", available at: www.kizilay.org.tr/Upload/Dokuman/ Dosya/89840457_haziran-2015-suriye-insani-yardim-operasyonu.pdf (accessed June 23, 2016).

TRC (2016), “Turkish Red Crescent meeting notes”, Jeddah.

UNHCR (2007), Handbook For Emergencies, UNHCR, available at: www.ifrc.org/PageFiles/95884/D.01.03 (accessed June 23, 2016).

UNHCR (2016a), “The UN Refugee Agency. What is a refugee?”, available at: www.unrefugees.org/ what-is-a-refugee (accessed January 18, 2016).

UNHCR (2016b), "Total persons of concern, in Turkey", available at: http://data.unhcr.org/ syrianrefugees/country.php?id=224 (accessed January 18, 2016).

UNHCR (2016c), “Operations in Turkey”, available at: http://reporting.unhcr.org/node/2544 (accessed January 18, 2016).

UNHCR (2016d), "Bosnia and Herzegovina regional office", available at: http://reporting.unhcr.org/ node/12002\#_ga=1.221477905.865779010.1466775782 (accessed June 23, 2016).

UNHCR (2016e), “The UN Refugee Agency. Biometric cash assistance”, available at: http://innovation. unhcr.org/labs_post/cash-assistance/ (accessed June 23, 2016).

UNHCR (2017), "Total persons of concern, in Egypt, Iraq, Jordan, Lebanon, Turkey, and North Africa", available at: http://data.unhcr.org/syrianrefugees/regional.php (accessed November 29, 2017).

Van den Bergh, J., Belien, J., De Bruecker, P., Demeulemeester, E. and De Boeck, L. (2013), "Personnel scheduling: a literature review", European Journal of Operational Research, Vol. 226 No. 3, pp. 367-385.

Van Wassenhove, L.N. (2006), "Humanitarian aid logistics: supply chain management in high gearf", Journal of the Operational Research Society, Vol. 57 No. 5, pp. 475-489.

\section{Corresponding author}

Bahar Y. Kara can be contacted at: bkara@bilkent.edu.tr

For instructions on how to order reprints of this article, please visit our website:

www.emeraldgrouppublishing.com/licensing/reprints.htm

Or contact us for further details: permissions@emeraldinsight.com 